\title{
EFFICACY OF MONTELUKAST ON TREATMENT OF WHEEZING LOWER RESPIRATORY TRACT INFECTION (LRI) IN YOUNG CHILDREN WITH RISK OF ASTHMA
}

\author{
N. Prapphal, S. Hantragool, J. Deerojanawong, S. Sritippayawan, R. Samransamraujkit
}

Department of Pediatrics, Chulalongkorn University, Bangkok, Thailand

Background and aims: Leukotrienes are major inflammatory mediators in wheezing-LRI and leukotriene antagonist has been reported to be effective in asthmatic children. This randomized double-blind, placebocontrolled trial study was performed to evaluate the efficacy of montelukast in the treatment of wheezingLRI and in prevention of recurrent wheezing among previously healthy children under 5 years of age with risk of asthma.

Methods: The enrolled patients were randomly allocated into the studied group (receiving 4-mg montelukast once daily while being hospitalized) and the control group (receiving placebo). The 2 groups were compared in terms of clinical severity scores, duration of oxygen use, length of hospital stay, chest X-ray, viral study and urine leukotriene $\mathrm{E}_{4}$ levels. All patients were followed up for 6 months to evaluate their recurrent wheezing episodes and pulmonary function tests.

Results: 21 patients (mean age 23 months) were recruited. 11 patients received montelukast, 10 patients received placebo. There were no differences in clinical severity scores, duration of $\mathrm{O}_{2}$ therapy, length of hospital stay and urine leukotriene $\mathrm{E}_{4}$ levels between the two groups. During the 6-month-follow up period, the montelukast group had lower recurrent wheezing episodes and inhaled corticosteroid use but not statistically significant. The airway resistance was significantly decreased after 6 months in the montelukast group (mean of difference $=-0.14, p=0.004$ ).

Conclusion: In wheezing-LRI children with risk of asthma, montelukast was ineffective in improving acute outcomes and prevention of recurrent wheezing. However; montelukast might be beneficial in decreasing airway resistance. 